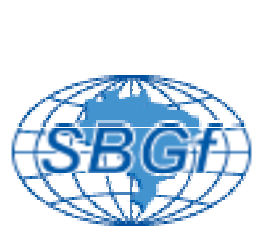

\title{
Métodos Geoelétricos aplicados no mapeamento de contaminação por disposição clandestina de resíduos domésticos
}

Georgia Castro de Souza, Vagner Roberto Elis \& Marta Sílvia Maria Mantovani

Instituto de Astronomia, Geofísica e Ciências Atmosféricas da Universidade de São Paulo( IAG-USP )

Copyright 2004, SBGf - Sociedade Brasileira de Geofísica

Este texto foi preparado para a apresentação no I Simpósio de Geofísica da Sociedade Brasileira de Geofísica, São Paulo, 26-28 de setembro de 2004. Seu

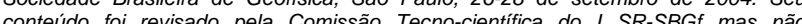
conteúdo foi revisado pela Conissão Tecno-cienifica do I SR-SBGf mas não necessariamente representa a opiniăo da SBG ou de seus associados. E proibida a reprodução total ou parcial deste material para propósitos comerciais sem prévia autorização da SBGf.

\section{Resumo}

A Geofísica aplicada ao estudo de contaminação de águas subterrâneas se mostra de grande importância pois vem apresentando resultados satisfatórios na caracterização de áreas contaminadas, fornecendo informações para os projetos de recuperação.

O estudo deste projeto está relacionado a áreas em que há disposição clandestina de resíduos domésticos sólidos e líquidos. Os locais afetados estão dentro do Parque de Ciências e Tecnologia , Cientec.

A área do parque situa-se na região da Água Funda, próxima a divisa dos municípios de São Paulo, São Bernardo do Campo e Diadema.

Neste local foram coletados dados geofísicos, que posteriormente foram analisados e interpretados para obtenção de informações sobre a forma e o comportamento da pluma de contaminação.

\section{Introdução}

Atualmente existe uma tendência mundial das populações concentrarem-se cada vez mais em áreas urbanas. Essa concentração populacional e o conseqüente aumento da produção de resíduos domésticos e industriais, vêm gerando muitos problemas relacionados a forma de disposição desses resíduos. Estes compreendem uma extensa gama de substâncias químicas que são dispostas no ambiente, muitas vezes, de forma totalmente inadequada, sem observar critérios mínimos para a proteção dos recursos hídricos subterrâneos. A disposição inadequada desses resíduos pode permitir a infiltração de líquidos contendo substâncias contaminantes até atingir as águas subterrâneas, comprometendo sua qualidade e podendo até inviabilizar seu uso (Elis, 1999). Além destas, outras atividades podem eventualmente comprometer a qualidade das águas subterrâneas como a agricultura , mineração, geração de energia, etc. Assim, a poluição das águas subterrâneas é normalmente atribuída a alguma forma de atividade intensiva como conseqüência da civilização humana. Essa afirmação torna-se mais evidente pela existência de várias formas de rejeitos: sólidos, líquidos - químicos e combustíveis, porém, não indica que todo empreendimento será causador de contaminação.

Do ponto de vista da contaminação das águas subterrâneas, o material que oferece risco é, em sua maior parte, representado pelos resíduos orgânicos, lixo hospitalar e outros resíduos domésticos que podem ser potencialmente perigosos. Assim a contaminação das águas subterrâneas ocorre através da percolação de águas pluviais e outros líquidos gerados pela própria degradação dos resíduos, que por infiltração no solo sob o aterro atingem o nível d'água. O líquido derivados desse processo de percolação através dos resíduos é denominado de chorume.

Essa situação, por sua vez, estimula os profissionais ligados às Ciências da Terra a pesquisar novos caminhos para estudar, avaliar e procurar novas soluções que possam minimizar os efeitos danosos causados pela disposição de resíduos em interação direta com o meio físico. Dentre esses caminhos pode ser enquadrado o uso de técnicas geofísicas.

A natureza dos métodos geofísicos, aliados ao baixo custo operacional e rapidez e facilidade de aplicação dos ensaios, torna-os particularmente adequados para aplicação no estudo de tais problemas. Uma justificativa ainda mais forte para a aplicação da geofísica, além das citadas acima, é que algumas técnicas fornecem dados contínuos sobre o local estudado, podendo, portanto, reduzir muito a necessidade de dados diretos e específicos, assim como permitem uma análise temporal e espacial mais detalhada.

Os métodos elétricos e eletromagnéticos vem se mostrando favorável aos estudos de áreas de disposição de resíduos urbanos, pois é possível identificar estes locais com a presença do chorume. Estes métodos geofísicos permitem investigar de forma contínua vários níveis do local, fornecendo como resultado seções de resistividade e/ou condutividade aparente e quando desenvolvida uma malha de ensaios, pode-se, ainda, fornecer mapas de resistividade e/ou condutividade aparente para várias profundidades investigadas.

\section{Metodologia/ Problema Investigado}

Em áreas de ocupação por população de baixa renda muitas vezes a coleta de lixo e o saneamento básico não é tratado com a mesma importância dos locais ocupados pelas classes sociais mais favorecidas. Esse fato associado ao baixo nível cultural reflete-se no tratamento dado aos resíduos que essa população produz, que são muitas vezes descartados em terrenos a céu aberto nas proximidades, de forma que a comunidade convive com a maioria do lixo produzido. Problemas dessa natureza são observados em alguns pontos do Parque de Ciências e 
tecnologia - Cientec, onde ocupação irregular de terrenos nos limites do parque são pontos degradados pela disposição de resíduos domésticos. Dentro desse contexto, este trabalho objetiva detectar e avaliar a contaminação causada por disposição de resíduos domésticos e esgotos em pontos dentro do Parque para posteriormente fazer uso desses resultados como forma de conscientização e integração social com a população responsável pela contaminação.

A área do parque situa-se na região da Água Funda, próxima a divisa dos municípios de São Paulo, São Bernardo do Campo e Diadema. Na figura 1, abaixo, temse o mapa geológico e de localização da área.
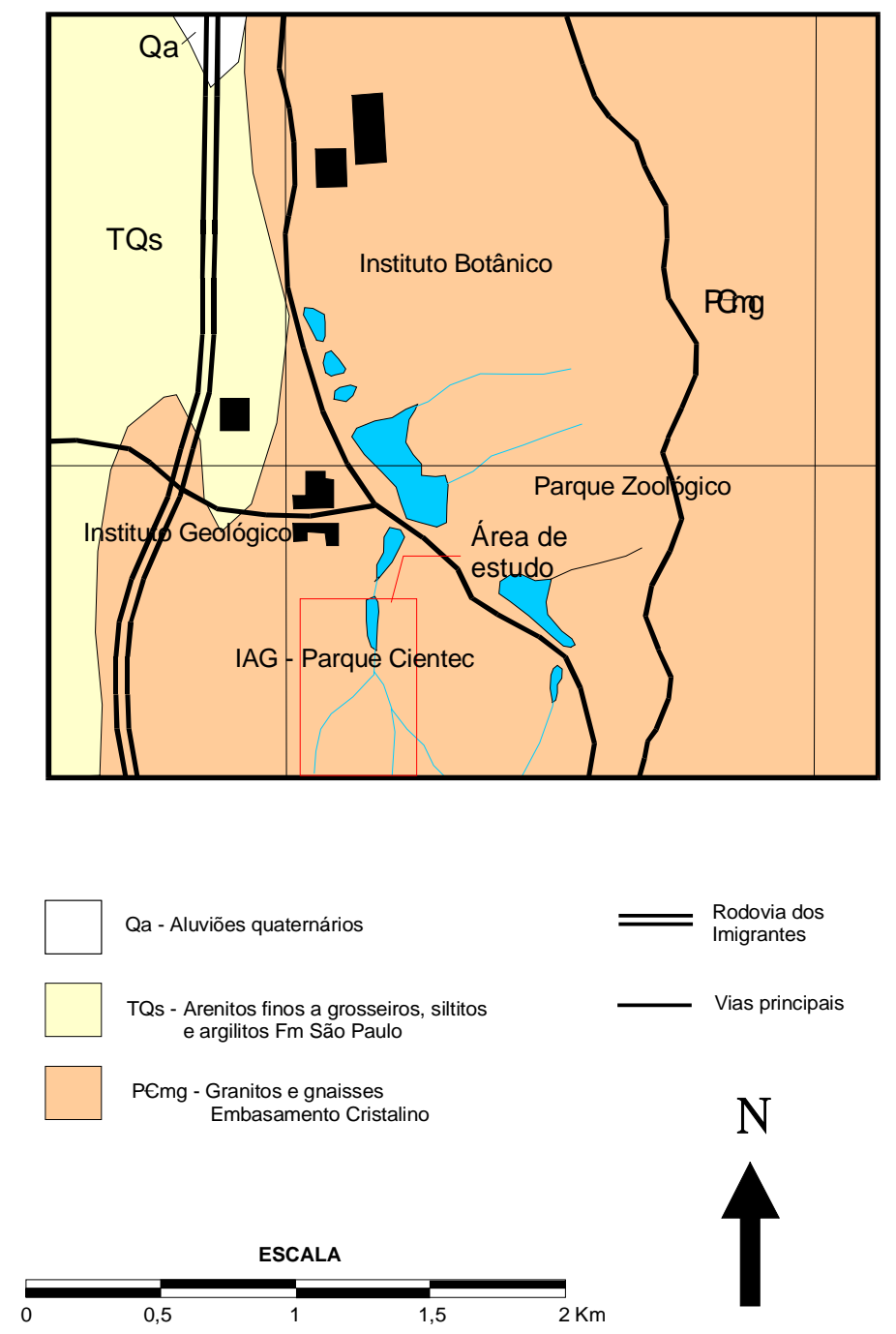

Figura 1: Mapa da região do Parque Cientec.
No Parque existem dois locais problemáticos.

- Um ponto há lançamento de resíduos líquidos de esgoto sanitário das casas construídas em local de invasão. Este local é denominado de área 1.

- $\quad$ No outro ponto há deposição clandestina de resíduos sólidos e líquidos caracterizando um pequeno "lixão". Este local é denominado de área 2.

Os métodos utilizados neste estudo são a eletrorresistividade e o eletromagnético indutivo. Desta forma é possível se ter uma informação pontual na observação da variação vertical do parâmetro físico, a resistividade, a partir da Sondagem elétrica e medir diretamente a condutividade dos materiais geológicos, a partir do caminhamento eletromagnético.

O arranjo de campo utilizado na sondagem elétrica vertical foi o Schlumberger. O equipamento utilizado foi o resistivímetro francês de marca Iris, modelo Syscal $R 2$. Os valores de resistividade aparente obtidos são tratados em software de inversão 1D, fornecendo assim a curva de resistividade aparente, com a qual é possível ter um perfil geoelétrico e a interpretação quantitativa.

O equipamento aqui utilizado no caminhamento eletromagnético indutivo foi o EM34 produzido pela empresa Geonics. Este funciona a partir do princípio da indução eletromagnética, operando em baixos valores de indução (McNeil, 1980), o que permite que o equipamento leia-se diretamente valores de condutividade aparente do terreno. Os valores de condutividade aparente obtidos são plotados no programa Surfer 6.0 (Golden Software, 1995) e assim produzidos mapas, possibilitando observar de forma espacial e temporal os níveis de contaminação da área.

\section{Resultados}

Este projeto foi iniciado em maio de 2003. Em um primeiro momento foram feitos levantamentos geofísicos dentro do Parque de Ciência e Tecnologia - Cientec, onde se localizam as duas áreas que são fontes e disposição clandestina de resíduos sólidos caracterizando um pequeno "lixão" e um local de com resíduos líquidos de esgotamento sanitário de casas construídas em área de invasão que lançam as águas dentro do parque.

O trabalho foi realizado primeiramente em uma das áreas afetadas pela disposição clandestina de resíduos. $\mathrm{Na}$ área 1, onde ocorre lançamento clandestino de esgoto, foi executada uma sondagem elétrica. $O$ ensaio foi feito com o aparelho Íris Syscal R2, sendo uma " linha" paralela e próxima, aproximadamente 1 metro, do muro existente no local, que separa o parque da rua, com espaçamento $A B / 2$ de 80 metros. Foi utilizado 0 programa de inversão que forneceu um modelo geológico do local, onde é possível identificar uma camada de solo contaminado por esgoto com 62,5 ohm.m, outra de solo natural com 170 ohm.m, a zona saturada a 6,4 m de profundidade (51,8 ohm.m) e a rocha inalterada com 1035 ohm.m.

O caminhamento elétromagnético foi realizado com 0 cabo de 10 metros, de forma a estudar as profundidades 
teóricas de investigação de 7,5 e 15 metros, isto é, os dados foram coletados com as bobinas na vertical (VL) e com as bobinas horizontal $(\mathrm{HL})$, respectivamente. Foram feitas linhas de aproximadamente 100 metros cada, todas aproximadamente paralelas, abrangendo áreas mais contaminadas, para as linhas mais próximas a divisa do Parque, e áreas menos contaminadas, para as linhas mais distantes que adentram a mata do parque. Posteriormente foi utilizado o programa Surfer 6.0 (Golden Software, 1995) onde os dados foram analisados e foi feito um mapa para os dados com as bobinas na vertical (VL) em que a profundidade alcançada é de 7,5 metros de profundidade, e um mapa para os dados com as bobinas na horizontal $(\mathrm{HL})$, em que a profundidade atingida é de 15 metros. Desta forma é possível analisar a pluma de contaminação de formas diferentes.

A figura 2 caracteriza a situação da contaminação na área 1, a uma profundidade de $7,5 \mathrm{~m}$, no mês de dezembro de 2003. É possível que a porção SE da área, onde estão localizadas as casas, apresenta valores de condutividade aparente mais elevados (acima de 8 $\mathrm{mS} / \mathrm{m}$ ), o que caracteriza a influência do lançamento dos resíduos diretamente no solo.

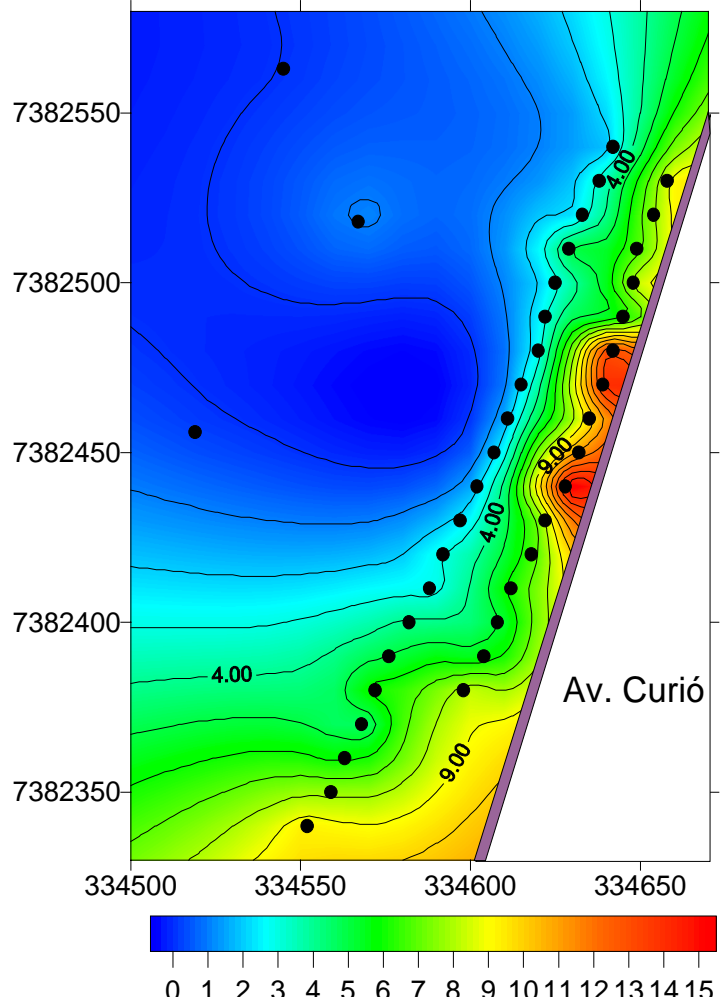

Figura 2: Mapa de condutividade aparente com profundidade de $7,5 \mathrm{~m}$, da área 1 .

A segunda área estudada é a região caracterizada pelo "lixão", com disposição de resíduos líquidos e sólidos. Neste local foi utilizado o mesmo procedimento da área 1 para coleta de dados elétricos e eletromagnéticos. Foi executada uma sondagem elétrica gerando também um modelo geológico do local, onde se identifica uma camada de resíduos superficiais (lixo seco) com resistividade de 408 ohm.m, outra camada com resíduos mais úmidos com resistividade de 153 ohm.m, uma camada de solo contaminado saturado com resistividade de 47,2 ohm.m a aproximadamente $10,5 \mathrm{~m}$ e a rocha inalterada com 1593 ohm.m.

Foram realizados também ensaios geofísicos de caminhamento elétrico na área 2 nos meses de setembro de 2003 e março de 2004. Estes dados eletromagnéticos foram analisados e apresentados sob a forma de mapas de condutividade elétrica das duas áreas, podendo assim caracterizar a pluma de contaminação e obter uma visualização da variação temporal desta.

As figuras 3 e 4 ilustram a contaminação da área 2 a uma profundidade de $7,5 \mathrm{~m}$ para os meses de setembro de 2003 e março de 2004 respectivamente.

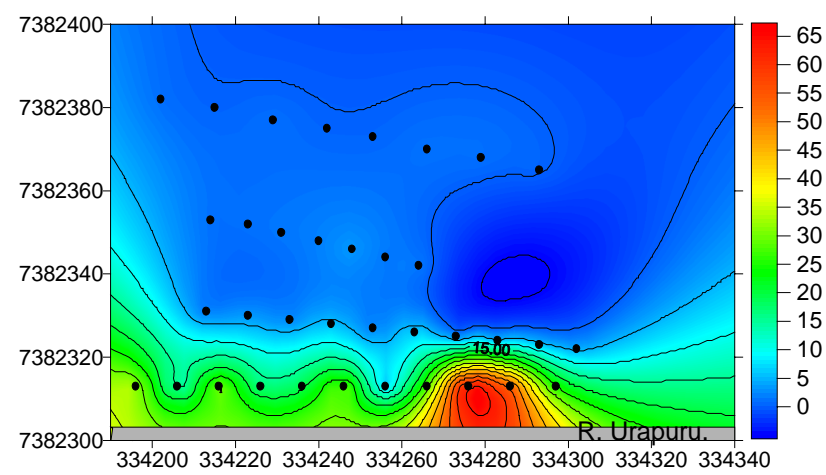

Figura 3: Mapa de condutividade aparente da área 2 do mês de setembro de 2003.

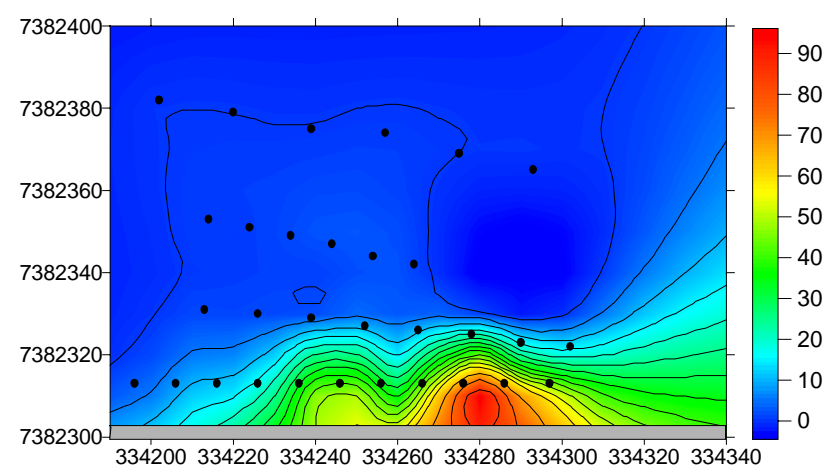

Figura 4: Mapa de condutividade aparente da área 2 do mês de março de 2004.

Como pode ser observado, os valores de condutividade mostram a posição da área afetada. O "lixão" localiza-se próximo das coordenadas $334.280 \mathrm{~m}$ E e $7.382 .310 \mathrm{~m} \mathrm{~N}$, onde tem-se valores de $65 \mathrm{mS} / \mathrm{m}$ na época de menor pluviosidade e $95 \mathrm{mS} / \mathrm{m}$ nos dados coletados em março de 2004, no período de chuvas. Como este depósito está posicionado em uma cota alta, nota-se que a dispersão da contaminação se dá para os sentidos E e W do local, mas não para $\mathrm{N}$, que é o sentido para o interior do parque. Comparado com a área 1, pode-se observar que 
para área 2 (com disposição de resíduos sólidos e líquidos) a contaminação se dá de forma mais acentuada principalmente em superfície. Outra observação, já citada acima, é que nos meses com alto índice pluviométrico, como março (período posterior as chuvas) a contaminação se acentua ainda mais.

$\mathrm{Na}$ área 1 , região com disposição principalmente de resíduos líquidos, a contaminação é menos acentuada, no entanto se apresenta também principalmente na superfície. Já a relação da contaminação com o índice pluviomérico não é tão forte pois o poder de dispersão superficial destes resíduos é maior, diminuindo a concentração dos resíduos.

\section{Discussão e Conclusões}

A partir das informações obtidas e da analise do local vemos que realmente ambas as áreas possuem altos níveis de contaminação por resíduos sólidos residenciais e esgoto.

Pela comparação das sondagens elétricas realizadas em cada área observa-se que a área 2 possui valores menores de resistividade, o que deve-se ao fato de que nesta área é encontrada grande quantidade de resíduos em superfície alem do esgoto a céu aberto. Na área 1 observa-se lançamento de esgoto e uma menor quantidade de resíduos. Apesar das áreas serem um pouco distantes entre si, o topo do embasamento tem aproximadamente a mesma profundidade de cerca de $15 \mathrm{~m}$.

Analisando os mapas eletromagnéticos podemos observar que a área 2 possui valores maiores de condutividade aparente que a área 1, isto pela área 2 apresentar maiores quantidades de resíduos. É possível ver também que os valores maiores de condutividade aparente ocorrem nos dados coletados com a disposição $\mathrm{VL}$, pois os valores obtidos estão localizados em uma região mais superficial, onde se localiza as maiores concentrações da contaminação causada pelos resíduos. A partir das análises temporais na área 2, que é a mais problemática, é possível observar também que o fluxo da pluma de contaminação se direciona na posição contrária ao interior do Parque, onde há um lago, minimizando o potencial de contaminação do depósito de resíduos no sentido do parque. O fluxo se dirige para a zona invadida. Outro fato observado é que nos meses de chuvas os índices de contaminação estão acentuados, evidenciando que nesses períodos o problema de contaminação é potencializado.

\section{Agradecimentos}

Ao professor e orientador Vagner R. Elis, aos técnicos André Rugenski e Ernandi Costa Santos. Ao CNPq pela bolsa de IC concedida para a realização do projeto.

\section{Referências}

Elis, V.R., 1998. Avaliação da aplicabilidade de métodos elétricos de prospecção geofísica no estudo de áreas utilizadas para disposição de resíduos. Tese de
Doutorado, Instituto de Geociências e Ciências Exatas, UNESP, Campus de Rio Claro-SP, 264 p.

Golden Software, Inc., 1995. Surfer ${ }^{(\mathrm{tm})}$ for Windows V6. Reference Manual. Golden, Colorado - USA.

McNeill, J. D., 1980. Eletromagnetic terrain condutivity measurement at low induction numbers. Nota técnica no 6, Geonics; 